\title{
Over-perception about Land Use Changes: Assessing Empirical Evidence and Linkage with Decisions and Motivated Beliefs
}

\author{
Hongli Feng, Tong Wang, David A. Hennessy, Gaurav Arora
}

Working Paper 21-WP 626

November 2021

\author{
Center for Agricultural and Rural Development \\ lowa State University \\ Ames, lowa 50011-1070 \\ www.card.iastate.edu
}

Hongli Feng is Assistant Professor Professor, Department of Economics, lowa State University. Email: hfeng@iastate.edu.

Tong Wang is Assistant Professor, Department of Economics, South Dakota State University. Email: tong.wang@sdstate.edu.

David A. Hennessy is Professor, Department of Economics, lowa State University. E-mail: hennessy@iastate.edu.

Gaurav Arora is Assistant Professor, Department of Social Sciences and Humanities, Indraprastha Institute of Information Technology. E-mail: gaurav@iiitd.ac.in.

This publication is available online on the CARD website: www.card.iastate.edu. Permission is granted to reproduce this information with appropriate attribution to the author and the Center for Agricultural and Rural Development, lowa State University, Ames, lowa 50011-1070.

For questions or comments about the contents of this paper, please contact Hongli Feng, hfeng@iastate.edu.

lowa State University does not discriminate on the basis of race, color, age, ethnicity, religion, national origin, pregnancy, sexual orientation, gender identity, genetic information, sex, marital status, disability, or status as a U.S. veteran. Inquiries regarding non-discrimination policies may be directed to Office of Equal Opportunity, 3410 Beardshear Hall, 515 Morrill Road, Ames, lowa 50011, Tel. (515) 294-7612, Hotline: (515) 294-1222, email eooffice@iastate.edu. 


\title{
Over-perception about land use changes: Assessing empirical evidence and linkage with decisions and motivated beliefs ${ }^{1}$
}

Hongli Feng ${ }^{\mathrm{a}} \quad$ Tong Wang $^{\mathrm{b}}$ David A. Hennessy ${ }^{\mathrm{c}}$ Gaurav Arora $^{\mathrm{d}}$

\begin{abstract}
${ }^{a}$ Assistant Professor, Dept. of Economics, Iowa State University. Contact: hfeng@iastate.edu
${ }^{\mathrm{b}}$ Assistant Professor and Extension Specialist, Dept. of Economics, South Dakota State University. Contact: tong.wang@sdstate.edu

${ }^{\mathrm{c}}$ Professor and Elton R. Smith Chair in Food and Agricultural Policy, Dept. of Agricultural, Food \& Resource Economics, Michigan State University. Contact: hennes64@msu.edu ${ }^{d}$ Assistant Professor, Department of Social Sciences and Humanities, Indraprastha Institute of Information Technology Delhi, India, Contact: gaurav@iiitd.ac.in
\end{abstract}

\footnotetext{
${ }^{1}$ A version of this working paper is forthcoming in Land Economics.
} 


\title{
Over-perception about land use changes: assessing empirical evidence and linkage with decisions and motivated beliefs
}

\author{
Abstract: \\ Perception biases documented in the literature often pertain to subject matters that are difficult \\ to observe or measure such as one's ability. We study perception biases with respect to a \\ concrete indicator that can be objectively measured: land use changes in a local area. We \\ examine four hypotheses about land use change perceptions and test them with farm survey data \\ complemented by satellite data. We discover systematic biases in farmers' perceptions about \\ local land use changes that are consistent with motivated beliefs, and also evidence that links \\ perceptions with intended future land conversions. Alternative explanations and policy \\ implications are discussed.
}

Keywords: behavioral economics; farm survey; grassland conversions; human dimensions; land use policy; perception biases

JEL Classifications: Q1, Q5, D91 


\section{Introduction}

"Who says he's seeing this place the way we're seeing it? Humans see what they want to see."Rick Riordan, The Lightning Thief

An individual's decisions are shaped by her perception of circumstances as opposed to actual circumstances. Perceptions about data are not always consistent with the underlying data. ${ }^{1}$ Furthermore, people with the same available information can have systematically different beliefs (Akerlof and Dickens 1982; Bénabou 2015). Heterogeneous perceptions of qualitative measures are ubiquitous, e.g., people have different opinions on a landscape's beauty. But significant heterogeneity can also exist on perceptions about common quantitative measures. Perception biases have been documented in such complex measures as corruption within institutions (Olken 2009; Kraay and Murrell 2016; Friesenbichler et al. 2018), inflation rate (Georganas et al. 2014; Coibion et al. 2018), risk magnitude (Viscusi 1990; Botzen et al. 2015; Ziebarth 2018), college textbook prices (Matsumoto and Spence 2016) as well as in more concrete and observable measures of specific population attributes, including parental view of youngest child size (Kaufman et al. 2013) and average height (Merrill and Richardson 2009; Poston et al. 2014).

While people use information to form perceptions, there is much evidence to suggest that various factors impede our ability to process this information in an unbiased way. As perception biases can arise in many different contexts, it is important that we understand them within the conceptual context in which they arise. Some biases are related to our past experience, for example, Botzen et al. (2015) found evidence of bias in homeowners' perceptions about the probability of flood risk and the magnitude of damages, relating them to past experience and the location of homes. Homeowners who have (respectively, have not) experienced a flood recently are likely to overestimate (respectively, underestimate) the probability of a future flood. Some biases arise due to psychological needs, for example, Proto and Sgroi (2017) showed evidence 
of a powerful and ubiquitous bias in perceptions that are "self-centered" in the sense that those at extremes tend to perceive themselves as closer to the middle of the distribution than is actually the case. The self-centered perception biases are likely to be "self-serving" due to a form of subconscious "strategic ignorance" that caters to individuals" psychological needs. Another well-documented psychological motive for misperception is confirmation biases whereby an individual seizes on evidence that supports her current beliefs while ignoring evidence that conflicts with it (e.g., Rabin 1998). Rabin and Schrag (1999) shows that confirmatory bias can lead an agent to believe with near certainty a false hypothesis despite receiving an infinite amount of information. More recently, Fryer et al. (2019) introduced a model and an experiment to demonstrate that, when signals are open to interpretation, confirmatory biases can result in agents to have polarized views even when they observe the same information.

In this paper, we study perception bias issues in the context of land use changes which are critical for the health of ecosystems and the human communities that they encompass. It is increasingly recognized that "Land-use decision processes are influenced not only by the biophysical environment, but also by markets, laws, technology, politics, perceptions, and culture," (Brown et al. 2014). We aim to examine how perceptions regarding land use changes compare with reality and how these perceptions relate to land use decisions. The land use setting that we study is in the semi-arid United States Northern Great Plains, where the Western Corn Belt meets wheat production and grass-based feeder cattle production operations. The area contains large tracts of pothole wetlands and grasslands that provide hunting, duck nesting, pollinator feeding (Otto et al. 2016) and carbon sequestration services (Wang X. et al. 2017; Lu et al. 2018). The area has seen substantial grassland conversion since about 2006 (Wright and Wimberly 2013; Lark et al. 2015, Wimberly et al. 2017) to corn rotation systems (Green et al. 2018) although some reversion to grass occurred by 2017 (Wang T. et al. 2018). Crop output 
prices have been a factor in determining overall loss magnitude (Wang T. et al., 2017). For well over half a century branches of the U.S. Federal government have sought to protect grassland and wetland through the purchase of permanent easement property right, where more than 340,000 hectares were protected from conversion during 1998-2012 (Walker et al. 2013), but many wildlife-friendly grassland acres remain unprotected and high cropland prices can severely constrain Federal efforts to protect them. Thus, if perception biases exist and have realworld effects on conversion then they would generate significant social externalities.

The social externalities associated with perception biases have been examined in other areas such as perceptions about income distribution and how it affects preferences toward income redistribution policies, and the impacts energy cost of misperceptions on energy efficiency (Alesina 2018, Allcott 2011). Bennett (2016) highlighted the importance of using perceptions to improve conservation outcomes. Whether perceptions about land uses are consistent with reality can have important policy implications not only because an individual's perceptions directly affect her decisions but also because perception biases can have potentially profound indirect effects as regional land use changes often lead to agglomeration effects. For example, overperception of land use changes could lead to more native grassland being converted which may in turn trigger a cascading phenomenon (Arora et al., 2021). That is, as cropland area increases, infrastructure for agricultural crop production will expand and improve (Richardson 2009). The sorts of infrastructure at issue can take various forms including efficient logistics for transporting fertilizer, seed and pest control inputs, product storage and processing facilities and operations, as well as ensuring that distribution infrastructure is in place for shipping, say, ethanol or dried distillers' grains. This makes converting grassland to cropland more profitable, leading to more land conversion. Beyond these effects, perceived land use changes are often a driving force behind policy positions of interest groups including non-profit conservation organizations and commodity associations. Therefore, it is important that we understand 
perceptions about land use changes and the implications of biases, if any.

Interactions between farmers' perceptions and decision making have been studied in other contexts. For example, Adesina and Baidu-Forson (1995) found that farmers' subjective perceptions about the characteristics of new agricultural technologies capture data that are important in technology adoption decisions. Based on a survey of Iowa farmers in the United States, Arbuckle et al. (2013) also found evidence to support the importance of farmers' perceptions. Their results show that farmers who were concerned about the impacts of climate change on agriculture and attributed it to human activities had a more positive attitude toward adaptive and mitigative management strategies. A literature has also explored how learning about a technology accumulates and is then passed on determines a new technology's diffusion path (Conley and Udry 2010).

Although a very large body of work has examined reasons for and consequences of land use changes in general, including many in the same study area as ours (see, e.g., USGAO 2007; Rashford et al. 2011; Feng et al. 2013; Miao et al. 2014; Wang T. et al., 2017), and some work also exists on how people process landscape data (Dramstad et al. 2006; Kalivoda et al. 2014), to our knowledge ours is the first study that directly compares perception about land use changes with an objective measure of the same changes. We examine four hypotheses. We first posit that there are perception biases concerning land use changes in our study region. Next, we conjecture that, if a farmer made a conversion from grass to crop in the past then her current perception of land use changes in her locality is likely to be biased toward cropping. Third, we hypothesize that there is a positive relationship between past land conversions and perceptions about the extent of infrastructure changes. The last hypothesis claims that farmers who currently over-perceive cropping are more likely to express intentions for future conversion from grass to crop conditional on the availability of land to convert. We examine these hypotheses with satellite-based land use data and data from a farm survey. Discussions on alternative 
explanations for perception biases and likely policy implications are also provided.

\section{Study Setting and Hypotheses}

As we explain in the Introduction section, perception biases can arise in different contexts and there can be alternative explanations for those biases. In this section, we layout the setting of land use changes and perceptions in our study and introduce four hypotheses concerning perception biases, a related rationale, and connections with land use decisions.

\subsection{Factual settings for perception about land use changes}

In order to examine perceptions and related potential biases, it is necessary that we present the factual situation of land use and land use changes that are the object of perceptions and will provide a benchmark to evaluate perceptions in our study. Our study region is a primarily an agricultural area having two major land use types: croplands and grasslands. We focus on land use changes between crop and grass because these are the two major land uses in our study region (described in detail in the empirical sections), and would yield very different ecological outcomes. Grass cover is generally more beneficial in terms of water quality, wildlife habitat, and carbon sequestration while the main crops, especially corn, are more input intensive with higher adverse impacts on the environment.

Land is heterogeneous in terms of topology (e.g., slope), soil attributes (e.g., soil organic matter, soil texture, and water holding capacity), and climate conditions (e.g., daily maximal and minimal temperature, and monthly cumulative precipitation, especially during crop/grass growing seasons). We can use a composite index, $\theta \in[0,1]$, to capture the heterogeneity of land quality with higher value of $\theta$ representing higher productivity potential for both crop and grass. However, land with small values of $\theta$ generates a higher net return in grass than in crop while land with large values of $\theta$ generates a higher net return in crop than in grass. Figure 1 is an illustration of the relationship between $\theta$ and the net returns to grass and crop. Given a 
particular market price situation, there is one value of $\theta$ (e.g., $\theta^{*}$ at initial crop prices in Figure 1) at which grass and crop will generate the same net return. For lower values of $\theta$, net return is lower for crop than for grass. As $\theta$ increases, net return increases for both crop and grass but at a faster rate for crop; so net return to crop eventually exceeds that to grass and the difference increases further for higher values of $\theta$. This $\theta$ in empirics is represented by a land capability class index. Beyond $\theta$, a farmer's non-economic circumstances will also play an important role in her land use decisions.

When crop prices increase, as shown by the shifting up of net crop returns in Figure 1, more land will generate a higher net return in crop than in grass (indicated by the shift from $\theta^{*}$ to $\hat{\theta}$ in the figure). However, the extent of grassland to cropland conversion will also be affected by each individual farmer's specific economic and non-economic circumstances. For example, there will be conversion costs when switching from grass to crop or from crop to grass. This implies that land conversion decisions will not be determined by single-year net returns but rather by expected returns over multiple years. Different farmers may have different estimates or perceptions about the conversion costs. Plus, some farmers may have a strong preference for a lifestyle or family legacy that is associated with grass-based production. Such individual circumstances, related to both economic and non-economic factors, make it more challenging to gauge how much grassland will be converted to cropland as crop prices increase.

Our study area is the Northern Great Plains of the Dakotas. During the relevant period for our empirical study (i.e., 2004-2014), this region witnessed dramatic price increases for corn, soybean, and wheat, the three major crops in our study region. Up until 2006, corn prices mostly hovered around \$2/bushel. However, between 2007 and 2015, average local cash corn prices were above $\$ 3$, peaking in 2012 at about $\$ 6.7 /$ bushel. A similar trend occurred for soybean prices, which were rarely above \$7/bushel before 2006, but increased to \$9.6/bushel in 2007 and was above $\$ 14 /$ bushel in 2012 . Thus, the overall land use change during this period was 
conversion of grassland to cropland and an increase in total cropland area, as has been documented extensively by the literature (e.g., Wright and Wimberly 2013). The perceptions that we analyze next will be about beliefs of land use changes during our study period.

\section{Key features of factual setting as the object of perceptions:}

At the onset of our study period (2004-2014), where part of the land was cropped and the rest was under grass, an exogenous price shock occurred that favored crop prices relative to those of grass-based outputs. We will focus on land that was originally in grass because of the concerns surrounding grassland loss. Farmer $i$ as well as some other farmers in her locality, defined as within a certain radius (say, 5 miles) of farmer $i$ 's location, had land in grass, that is, $a_{i, 0}=g$ and $a_{j, 0}=g$ for some $j \neq i$, with " 0 " representing the beginning of the study period; these farmers were faced with the decision to stay in grass or to convert grass to crop given the increased crop prices. Some farmers converted from grass to crop including farmer $i$, i.e., $a_{i, 1}=c$ and $a_{j, 1}=c$ for some $j \neq i$, with " 1 " representing the end of our study period.

The perception related questions that we examine here are: (i) Were farmers' perceptions about percentage of land area converted to crop biased? (ii) If perceptions were indeed biased then what potential hypotheses could explain the gap? And finally, (iii) what were the likely connections between perception biases and land use decisions in the past or intention of land use changes in the future?

\subsection{Definition of perception biases in the context of land use changes}

In a world with complete information available at no cost and in the absence of cognitive biases, there would be no perception bias. Before we explain how biased perceptions can arise regarding land use and land use changes in the next section, here we explain how perception biases are defined. In our context, the extent of land use changes in a local area is a concrete measure that is observable and objectively measurable. Specifically, a farmer can visually 
observe land use and land use changes in her locality. The information a farmer likely does not have is the specific magnitude of overall changes, for example, the percent change in total cropland area in her locality. ${ }^{2}$ When asked about such values, a farmer will answer based on her perceptions. This context is similar to that in Proto and Sgroi (2017) where research subjects were asked to estimate their peers' average weight and height, among other measures, given that they saw their peers and visually observed their weight and height on a day-to-day basis in the same environment. What these research subjects did not have was explicit data on weight and height such as the average, the median, or the $90^{\text {th }}$ percentile of these body metrics. When asked about these measures by researchers, the subjects gave estimates based on their perceptions which were found to be systematically biased and the biases were found to be "self-centered" which means that individuals tend to see themselves as more "average" than is actually the case (Proto and Sgroi 2017).

Let $N_{i}$ be the set of farmers in farmer $i$ 's locality. Let $j$ for $j \in N_{i}$ represent a farmer in farmer $i$ 's locality. Also, let $\tilde{a}_{j, 1}$ be farmer $i$ 's perception about land use decisions of each farmer $j, \forall j \neq i$. To characterize perception biases, we first define $I\left(a_{j, 1}=a_{i, 1}\right)$ as a variable indicating whether farmer $j$ made the same land use decision as farmer $i: I\left(a_{j, 1}=a_{i, 1}\right)=1$ if the land use decisions are the same; otherwise, $I\left(a_{j, 1}=a_{i, 1}\right)=0$. Then $n_{i, 1} \equiv \sum_{j \neq i, j \in N_{i}} I\left(a_{j, 1}=a_{i, 1}\right)$ is the total number of farmers in farmer $i$ 's locality who actually made the same land use decision as farmer $i$. Similarly, $\tilde{n}_{i, 1} \equiv \sum_{j \neq i, i \in N_{i}} I\left(\tilde{a}_{j, 1}=a_{i, 1}\right)$ is the total number of farmers in farmer $i$ 's locality whom she perceives to have made the same land use decision as her own. The difference between $\tilde{n}_{i, 1}$ and $n_{i, 1}$, i.e., $\Delta \tilde{n}_{i, 1} \equiv \tilde{n}_{i, 1}-n_{i, 1}$, is farmer $i$ 's perception bias. By construction, farmer $i$ is not cognizant of her biases. Also, $\tilde{n}_{i, 1}$ and $\Delta \tilde{n}_{i, 1}$ do not have to be integers representing the number of farmers; they can be scaled to represent variations in 
perception biases. For example, the inverse of the total number of farmers in a farmer's local

area can be used as a scaling factor. Then the scaled $\tilde{n}_{i, 1}$ and $n_{i, 1}$ would represent, respectively, perceived and actual share of farmers who have made the conversion from grass to crop. Further, each farmer's conversion decision can be weighted by acres to represent the land share each farmer has. Then the scaled versions of $\tilde{n}_{i, 1}$ and $n_{i, 1}$ would represent perceived and actual proportions of land that had been converted from grass to crop. The latter definition is what we use in our empirical analysis. Whether there are biases and the extent of any biases are the foci of our research. Specifically, we will test the following hypothesis:

Hypothesis 1 (H1): There is no perception bias about the amount of land area that has been converted from grassland to cropland in a local area, i.e., $\tilde{n}_{i, 1}=n_{i, 1}, \forall i \in N_{i}$.

\subsection{Confirmation based rationale for perception biases in the context of land use changes}

Well-known in both psychology and economics literatures is the notion that perceptions are affected not only by objective happenings and the way we process such happenings, but also by our (sub-conscious) psychological needs (e.g., Rabin 1998, Bénabou 2015). For example, there is evidence that supports motivated visual perception, i.e., "we see what we want to see" (e.g., Balcetis and Dunning 2006). One manifestation of motivated beliefs is the tendency for confirmation bias: if we have made a choice, we would like to believe that others have made a similar choice. That is, there are psychological benefits to having the belief that our decision is "confirmed" by others' decisions as such confirmation can be perceived as "validation" of our choices. In our context, psychological needs can mean that a farmer desires that her neighbors' land use decisions be consistent with hers. Specifically, we conjecture the following, 


\section{Conjecture of Confirmation Effect: Given that a farmer has converted land from grass}

\section{to crop, the farmer will derive a higher utility if she believes others in her locality have}

\section{made a conversion in the same direction.}

Bénabou (2015) modeled motivated beliefs with a utility function that is a weighted average of the standard payoff directly resulted from own decisions and a component for psychological adjustments. We can use the following function, $\varpi_{i, 1}^{j}(\bullet)$ to capture such psychological adjustments:

(1) $\varpi_{i, 1}^{j}\left(\tilde{a}_{j, 1} \mid a_{i, 1}=c\right)\left\{\begin{array}{ll}>0 & \text { whenever } \tilde{a}_{j, 1}=c \text { given } a_{i, 1}=c, \\ =0 & \text { otherwise, }\end{array}\right.$ for $j \neq i$.

That is, $\varpi_{i, 1}^{j}(\bullet)$ represents a pair-wise confirmation effect when farmer $i$ compares her own decision with farmer $j$ 's decision: when farmer $i$ perceives that her neighbor has made the same decision as hers, her utility gets a boost. Otherwise, her utility is not affected. Based on such confirmation effects, we have the following hypothesis:

Hypothesis 2 (H2): Over-perception of land conversion from grass to crop is positively correlated with a farmer's land conversion decision from grass to crop.

As more land is converted to cropland, the local infrastructure for crop production will also expand and improve accordingly (Richardson 2009). Thus, the perception that total cropland has increased will likely lead to the perception that infrastructure has improved. Then, as an extension to Hypothesis 2, we conjecture that a farmer's perceived infrastructure condition will be positively linked to her land use decisions. When a farmer has the view that the infrastructure for corn and soybean has improved, all else equal, this will make growing corn and soybean more attractive than grass-based production, likely contributing to land conversion cascades whereby some conversion of grassland leads to more conversion of grassland. Such cascading effects have important implications for conservation policy design and have been examined by 
Arora et al. (2021). Nevertheless, it is harder to have a concrete objective measure of infrastructure improvement, and so we do not examine whether perceived improvement is overperception or not.

Hypothesis 3 (H3): Farmers who have converted from grass to crop are more likely to perceive an improvement in infrastructure for cropping.

The linkage between perception and farmers' decision making has been examined by the literature (e.g., Arbuckle and Roesch-McNally, 2015). In our context, this means that current perceptions about local land use changes may also affect a farmer's intention for future land use changes. Let $\tilde{a}_{i, 2}$ be the land use intention for $t=2$ (representing the future) that is expressed by farmer $i$ at the end of $t=1$ (representing the present). In canonical economic modeling, the conversion decision is determined by economic returns and own preferences (Plantinga 1996; Rashford 2011). In particular, if a crop is expected to bring higher net returns than grass (after conversion costs are accounted for), then conversion from grass to crops will be preferred; and vice versa. In our analysis, we examine to what extent, if any, perception of local land use changes plays a role in land conversion intentions. In particular, we posit that the probability of $\tilde{a}_{i, 2}=c$, denoted as $\operatorname{Prob}\left(\tilde{a}_{i, 2}=c\right)$, is affected not only by factors considered in traditional analyses such as land quality indicators and farmers' characteristics, but could also be affected by the farmer's perception biases about land use changes in local areas $\left(\tilde{n}_{i, 1}-n_{i, 1}\right)$ and her past land use decisions $\left(a_{i, 1}\right)$. The hypothesis regarding the role of perceptions on future conversions can be expressed as follows,

Hypothesis 4 (H4): Farmers who currently perceive more land conversion from grass to crop are more likely to express the intention to convert from grass to crops in the future ${ }^{3}$, i.e., 


$$
\frac{\partial \operatorname{Prob}\left(\tilde{a}_{i, 2}=c\right)}{\partial\left(\tilde{n}_{i, 1}-n_{i, 1}\right)}>0
$$

We will next present data and describe empirical methods that we use to examine the above four hypotheses.

\section{Data}

\subsection{Survey of farmers' land use decisions and perceptions}

A survey was conducted in 2015 on farmers in the eastern region (the Prairie Pothole Region) of the Dakotas, part of the U.S. Northern Great Plains, as shown in Figure 2. The survey asked farmers three types of questions, namely: (i) their land use changes in the preceding 10 years (2004-2014) and intended land use changes in the subsequent 10 years (2015-2025), (ii) perceptions about changes in land use and related infrastructure in their local area, and (iii) the ranking of factors that influence land use changes on their individual farms and in their local area. Our analysis combines these survey data with satellite land use data and also land quality indicators that allow an assessment of the extent to which farmers' perceptions on land use changes are consistent with satellite data.

A sample of 3,000 farm addresses was purchased from Survey Sample International (now Dyanta), a large company specializing in data analytics. We only included farms with at least 100 acres of cropland because our focus is on farmers who make decisions on a substantial amount of land area. A stratified sampling strategy was used so that counties with proportionally more farms overall had proportionally more farms included in our sample. Iowa State University's Survey Research Center was contracted to implement the survey and to enter data from returned surveys. Respondent mailing addresses are available to researchers. The survey was distributed and collected between early March and early May of 2015 using a Dillman Protocol involving an advance letter, an initial mailing, a postcard reminder, and a second mailing to non-respondents. The initial mailing included a cover letter, the 8-page questionnaire, a \$2 incentive and the return envelope. In total 1,050 completed surveys were 
received, giving a survey response rate of $36.2 \%$ in the eligible sample (i.e., the original sample excluding non-deliverable addresses).

\subsection{Land use data based on satellite images}

We obtained actual land use data from the Cropland Data Layer (CDL) of USDA National Agricultural Statistics Service (USDA-NASS). The CDL data is a geospatial, crop-specific data product that is free for download through the CropScape (USDA-NASS, 2021a) platform. The CDL is assembled annually for the continental United States using signal processing of satellite imagery and extensive agricultural ground-truthing. The first year when CDL became available varies by state. For South Dakota, CDL data are available commencing 2006 while for North Dakota the data are available commencing 1997. Based on high-resolution satellite images, CDL data provides high spatial resolution. There is a growing literature that uses the CDL data to analyze crop and land use trend (e.g., Wright and Wimberly 2013, Wang, Y., et al. 2020, and Pates and Hendricks, 2021). These data are most reliable for corn and soybeans but less so for grass cover based on the extensive studies by the relevant literature ${ }^{4}$, e.g., Kline et al. (2013), Laingen (2015), Reitsma et al. (2016) and Lark et al. (2017), and Lark et al. (2021). For grass, the CDL overlays its agricultural classes on the National Land Cover Database (NLCD) grass data. ${ }^{5}$ User accuracy is not available for grass and is low. Due to this data limitation, Note that we are only considering changes in corn and soybeans areas from 2006 to 2014, no changes on grassland areas were estimated. Instead, we included the NLCD measured percentage of grassland, hay and pasture areas within the 5-mile radius in 2006 to capture the potential for converting more grassland to cropland.

The CDL data are employed to measure the actual land use changes in a respondent's locality to be compared with the respondent's perceived land use change. Besides questions regarding own land use changes, our survey asks about land use changes in the local area in the preceding 10 years as well as intentions for the subsequent 10 years. This area is specified in the 
survey questionnaire as a 5-mile radius centered on the respondent's location. Changes in corn, soybean areas are measured as the changes from 2006 to 2014 given that 2006 was the first year that CDL data were available for South Dakota. As a robustness check, we also use temporal smoothing to mitigate potential measurement errors of CDL data; specifically, we use the average of corn and soybean acres in 2013, 2014, and 2015 to represent corn and soybean acres in the ending year, 2014. We did not use temporal smoothing for the beginning year as CDL does not have data for earlier years in South Dakota.

\subsection{A summary of survey data and land use data based on satellite images}

Key variables from survey and CropScape data are provided in Table 1, which includes summary statistics for three categories: 1) farmer and farm characteristics; 2) perceptions about land use changes in the area; and 3) farmer conversion histories and intended future conversion decisions as well as perceived changes in infrastructure for corn production in the area. Of the first survey data category, average cropland acres operated is 1,226 while average total farm acres is 1,686 acres. Farmer's age, land tenure and off-farm employment are discrete choice variables with coding explained in the note of Table 1 . Respondent operations generally had smaller acreage than non-respondent operations in our eligible sample. For respondents, the average for corn, soybean, and total planted acres was 386,416 , and 1083, respectively. For non-respondent operations, the corresponding acres were $13.5 \%, 10.5 \%$, and $12.7 \%$ larger, respectively. Additionally, the average total farm size was 1286 acres for our survey respondents, which was $6.8 \%$ larger than the corresponding average (1198 acres) for the two Dakota states based on the 2012 US Census of Agriculture. This size difference is most likely due to our screening criterion whereby only farms with larger than 100 acres of cropland were considered for our sample. By design our sample does not represent very small farms.

Average farmer age is between the 50-59 and 60-69 year ranges. Land tenure is between the 'owned about half' and 'rent most operated acres' categories. The off-farm employment 
categorical variable signifies that most respondents have farming or ranching as their principal occupation. The farm location variable indicates that the survey area spans 4.93 degrees in latitude and 4.32 degrees in longitude. Soil quality is measured by the land capability classification (LCC) system (Helms, D., 1992; Wang T. et al., 2017), which captures the extent of limitation for crop production and is made available by the U.S. Department of Agriculture Natural Resource Conservation Service (NRCS). Classes I and II soils have few limitations for crop production, where limitations might include slope, soil depth and composition and disposition to erosion. Class III soils have moderate limitations for crop production. Class IV soils are very marginal for crop production although they may be cropped if convenient for farm operations. Classes V-VIII soils are seldom cropped. On average, 92.7 percent of land in our survey has soil quality in classes I-III. Land slope of no larger than 3 degrees also accounted for nearly $50 \%$. These numbers indicate that there is potential for land use conversion in the study region.

Of the second survey data category, questions about perceived past and prospective future land use changes are included. An example of a specific question is "How do you think the amount of the following types of grassland and cropland, within 5 miles of your farm operation base, has changed over the past 10 years?" We focus on changes in corn and soybean acres because this CDL category has high accuracy for this type of land. The variables are discrete choice encodings as explained in the Table 1 note. The category average is 4.3 for perceived changes in corn and soybean acres. As to objectively measured changes, CropScape data indicates that within 5-mile radius of the farm cropland acres, which is the focus of our empirical analysis, land used for corn and soybean increased by 3 percentage points on average from year 2006 to 2014 .

Of the third survey data category, about a quarter of farmers converted some portion of grassland to cropland in the 10 years prior to 2015 , a decade in which corn and soybean prices 
were significantly higher than historical levels as explained earlier. Looking 10 years beyond 2015, the percentage of farmers who plan to convert more grassland to cropland dropped to $15.8 \%$. This was likely a result of the reversal of crop price trend after 2013 , or the constraint in available land after much conversion in the local area. Even though only $15.8 \%$ of farmers intended to convert grassland and the number was much lower than the prior decade, it would still be a cause for concern regarding grassland loss. The average for perceived local change in infrastructure for corn is 3.8, which is between 'stayed about the same' and 'somewhat better.'

\section{Empirical methods}

\subsection{Existence of perceptions biases on cropland area in the studied region (Hypothesis 1)}

To formally examine H1, that there is over-perception in land use change for cropping, we first characterize perception biases in: (a) (mis)matched categories of actual and perceived land use changes; and (b) the number of respondents falling into each category. We also calculated average biases by taking the difference between land use changes as measured by CDL data and land use changes as perceived by farmers. As noted earlier, the perceived land use changes are measured as discrete variables in five categories whereas land use changes based on CDL data are continuous variables. To calculate the difference between perceived and measured land use changes, we chose the mid-point in each perception category as the perceived land use changes. For example, positive $7.5 \%$ is chosen for the category "increased by $5-10 \%$ ", and $0 \%$ is chosen for "stayed about the same (-5\% to 5\%)". We used $15 \%$ in our analysis for the two extreme categories "decrease (increase) by more than 10\%."

\subsection{Relationship between current perceptions and past land use decisions (Hypotheses $2 \& 3$ )}

Farmers' survey responses regarding their perceptions of changes in land uses and infrastructure take values that have an intrinsic order, enabling us to apply the ordinal logistic regression model (Wooldridge, 2010). For land use changes in the locality, the five categories are: $\geq 10 \%$ decrease, $5-10 \%$ decrease, within $\pm 5 \%, 5-10 \%$ increase, and $\geq 10 \%$ increase. Similarly, for 
infrastructure, the five categories are: much worse, somewhat worse, stayed about the same, somewhat better, much better. We label these responses, in the order given, as 1 through 5 . Let $\tau_{i, j}=\operatorname{Pr}\left(Y_{i}=j\right)$ for $j \in\{1,2, \ldots, 5\}$ be the probability that respondent $i$ will choose change category $j$. We define the cumulative probability $\left(\varphi_{i, j}\right)$, the probability of choosing a higher degree of impact, as $\varphi_{i, j}=\operatorname{Pr}\left(Y_{i} \geq j\right)=\sum_{l=j}^{5} \tau_{i, l}$ where $\varphi_{i, 5}=\operatorname{Pr}\left(Y_{i} \geq 5\right)=\tau_{i, 5}$ and $\varphi_{i, 1}=1$. Clearly the cumulative probability function, $\varphi_{i, j}$, (weakly) increases as response value $j$ decreases. Define the cumulative logit link as $\log \operatorname{it}\left(\varphi_{i, j}\right)=$ $\log \left[\varphi_{i, j} /\left(1-\varphi_{i, j}\right)\right]=\log \left[\operatorname{Pr}\left(Y_{i} \geq j\right) / \operatorname{Pr}\left(Y_{i}<j\right)\right]$ for $j>2$. To estimate the impacts of past land use decisions on perceptions, we employ the following proportional odds model:

$$
\operatorname{logit}\left(\varphi_{i, j}\right)=\alpha_{j}+\beta_{1} n_{i}+\beta_{2} a_{i}+\gamma W_{i}+\eta_{i, j}, \quad j \in\{2,3, \ldots, 5\},
$$

where $\eta_{i, j}$ represents the error term. If other variables in the above equation are fixed at 0 then $\alpha_{j}$ represents the log odds of choosing $Y_{i} \in\{j, \ldots, 5\}$ instead of $Y_{i} \in\{1, \ldots, j-1\}$.

The explanatory variable of primary interest is $a_{i}$, which is an indicator variable with $a_{i}=1$ representing past land use decisions to convert grass to crop. A positive $\beta_{2}$ that is statistically significant provides support for Hypotheses 2 and 3. For Hypothesis 2, the dependent variable is the category of perceived change in corn and soybean area; for Hypothesis 3 , the dependent variable is the category of perceived change of infrastructure for corn. The other variables in equation (3) are control variables. Variable $n_{i}$ represents actual land use changes in the recent past in farmer $i$ 's local area. We consider two groups of variables for inclusion in vector $W_{i}$ : (a) farm and farmer attributes which include farm size, and tenure status, and farmer's age; and (b) land and land use characteristics in a respondent's locality which include the fraction of land within 5 miles that was under grass in 2006; directional variables 
representing, respectively, degrees latitude north and degrees longitude west; the fraction within land capability classes I-III; and the fraction that has slope $\leq 3$ within 5 mile radius.

Some comments are in order for the model in equation (3). First, the model assumes a different equation for each category except the first category which is used as a base category. Second, the model assumes that categorization does not affect the impacts of the explanatory variables on the odds, with implication that coefficients for different explanatory variables are common across system equations such that only the intercept term differs. These cross-equation restrictions will be imposed automatically in the system. When compared with the multinomial logit regression model, the proportional odds model is more parsimonious in that fewer coefficients are estimated (Harrell 2015).

\subsection{Relationship between current perceptions and future land use intentions (Hypothesis 4)}

We use a logistic regression to capture the relationship between the probability of intending land conversion in the future and current perceptions about land use changes along with other control variables,

$$
\operatorname{Prob}\left(\tilde{a}_{i, 2}=c\right)=\alpha_{0}+\delta_{1} a_{i, 1}+\gamma_{1}\left(\tilde{n}_{i, 1}-n_{i, 1}\right)+\lambda W_{i}+\varepsilon_{i},
$$

with $\varepsilon_{i}$ as the error term, $a_{i}$ representing past land use decisions, and $W_{i}$ representing a vector of control variables similar to that for equation (3). Coefficients $\alpha_{0}, \delta_{1}, \gamma_{1}$, and $\lambda$ are to be estimated. A positive $\gamma_{1}$ would suggest that operators are more likely to convert grass to crop if she has a positive perception bias about changes in total cropland area.

\section{Results}

\subsection{Perceived vs actual land use changes (Testing Hypothesis 1)}

The mean actual change in corn and soybean area, as measured by CropScape data, is 3.1\%. The perceived cropland changes averaged $9.8 \%$, which is 6.7 percentage points higher than the actual CropScape data and a $t$ test statistic shows the difference to be statistically significant. So 
regarding percentage increase in the area of corn and soybean, on average farmers' perceived change was much higher than the actual rate as recorded in CropScape - this is an evidence rejecting Hypothesis 1 that there is no perception bias about land use changes. Table 2 compares survey data with those from CropScape by showing matching and mismatching categories of changes in corn and soybean area. The rows are based on the survey data representing perceived changes and the columns are based on CropScape data representing actual changes in corn and soybean area. Table 2 indicates that 499 respondents chose the top category ("Increased by $10 \% ")$ and 836 respondents chose " $5-10 \%$ " or higher in answering the survey question about land use changes. On the other hand, 764 respondents fell in the "Within 5\%" category based on Cropscape data. The numbers in diagonal cells show the number of respondents whose perceptions match actual changes while off-diagonal cells show the number of respondents whose perceptions differ from actual changes. The table has a clear pattern: just under $75 \%$ (747) of responses are below the diagonal and 4.5\% (45) are above the diagonal. These numbers indicate that there is over-perception relative to CropScape.

To better understand the nature of discrepancies between perceived and actual land use change, we divide the respondents into three groups depending on the extent of discrepancies in Table 2. Group I refers to the 5 diagonal shaded cells, on which the respondents' responses are consistent with CropScape data. Group II refers to the 8 cross-shaded cells, which are one cell off the diagonal, with modest discrepancies relative to CropScape values. The remaining 12 non-shaded cells belong to Group III, which are at least two cells removed from the corresponding CropScape values. We conducted Duncan's Multiple Range tests for the three groups on variables such as age, years operating the land, education level, off-farm employment status, acres operated, and land locations. We did not find a clear pattern in how perception accuracy changes with these variables: all of the differences between the groups are either statistically insignificant or small in magnitude. ${ }^{6}$ 


\subsection{Current perceptions about cropland area changes and past land use decisions: Testing}

\section{Hypothesis 2}

Respondents who converted in the past were more likely to choose the ' $5-10 \%$ increase' and '> $10 \%$ increase' categories than those who did not convert (about $88 \%$ vs $81 \%$, Appendix Table A1a). Table 3 a presents test results for $\mathrm{H} 2$ concerning the relationship between perceptions and past land use decisions based on the ordinal logit model in equation (3). Since very few respondents chose the two categories of decreasing cropland area, we combined 'decreased by $>10 \%$ ' and 'decreased by 5-10\%' and 'within 5\%' into a single category, referred to as the 'non-increase in cropland' category and labeled as ' 1 ' in the model. Consequently, 'increased by $5-10 \%$ ' and 'increased by $>10 \%$ ', are labeled as ' 2 ' and ' 3 ', respectively, and moving to a higher category indicates a larger increase in corn and soybean acres.

Results from four different models are presented in Table 3a. While model 1 only includes the previous conversion variable, farmer/farm characteristics are added in model 2 and the last two models further incorporate variables related to farm surrounding areas. As explained earlier, we calculated changes in corn and soybean areas with two types of ending values: one is the value in 2014 which is used in Model 3 and the other is the average of the values in 2013, 2014, and 2015 which is used in Model 4. Model 3 and Model 4 have largely the same results. For all models, the previous conversion decision from grass to crop has a statistically significant and positive impact on perceived cropland area changes. Note that the estimation results in this table are the exponential value of the coefficients in equation (3), representing estimated impacts of the variables on the odds ratio when a variable is increased by one unit. For example, for the variable "Conversion from grass to crop," results across all four models are quite similar, indicating that the odds of higher perception by farmers who converted grassland to cropland is at least 1.6 times that of farmers who did not convert. This result supports Hypothesis H2, i.e., 
those who converted grassland to cropland in the past 10 years are more likely to have perceptions of larger cropland area increases.

Regarding other control variables in the models, the effect of tenure index is significant at $1 \%$ level, increasing the odds of higher perception on cropland area change to about 1.2 times. When cropland in a local area increases by $1 \%$, the odds of perceiving more cropland change increases to about 1.05 times; the effect is significant at the $10 \%$ level for Model 3 and only significant at $0.15 \%$ for Model 4 . Percent of land in classes I through III was also found to be statistically significant although the effect is very small. Intuitively, perceptions about cropland area change were greater when a higher percentage of land in the area was suitable for crop production. Even after accounting for the other control variables, farmers in the north are found to have greater likelihood of perceiving higher cropland change: when latitude increases by one degree, the odds of perceiving greater change in corn and soybean areas increases to 1.6 times. This indicates farmers' perceptions on cropland change vary in different regions, which could potentially be due to influences of local media and outreach agencies such as university extension and Natural Resources Conservation Services.

\subsection{Perception about changes in infrastructure for corn production and past land use decisions (Testing Hypothesis 3)}

Respondents who converted in the past were more likely to perceive that the infrastructure to support corn production had improved when compared to 10 years earlier (Appendix Table A1b). In other words, they are more likely to choose the 'somewhat better' and 'much better' categories than those who did not convert (about $74 \%$ vs $63 \%$ ). Also, very few respondents chose the two worsened infrastructure change categories. So we combined 'much worse' and 'somewhat worse' and 'stayed about the same' into a single category, referred to as the 'nonimprovement in corn infrastructure' category and labeled as ' 1 ' in the model. Consequently, 'somewhat better' and 'much better', are labeled as '2' and '3', respectively. 
Table $3 \mathrm{~b}$ presents test results for $\mathrm{H} 3$ concerning the relationship between perceptions of corn infrastructure change and past land use decisions, based on the model in equation (3). The table presents results of four different models similar to those in Table 3a. For all models, the previous conversion decision from grass to crop has a statistically significant and positive impact on perceived infrastructure change in corn production. More specifically, results from all four models in Table $3 \mathrm{~b}$ indicate that the odds of perceiving better corn infrastructure among farmers who converted grassland to cropland is approximately 1.6 times that of those farmers who did not convert. Therefore, consistent with Hypothesis H3, those who converted grassland to cropland in the past 10 years are more likely to perceive that infrastructure had improved for corn production during that period.

Among farmer characteristics variables included in Table $3 \mathrm{~b}$, we can see that the number of operating years significantly decreases the odds of perceiving better corn production infrastructure. In other words, younger farmers are generally more optimistic about the improvement in corn infrastructure. Two other control variables on farm surrounding areas are significant in Model 3. One is latitude, suggesting that farmers in the north are more likely to perceive improvement in corn infrastructure. Distance to ethanol plants, considered as important infrastructure in corn production, also played a significant role in farmers' perception. Not surprisingly, farmers closer to an ethanol plant are more likely to perceive a positive change in corn production infrastructure.

\subsection{Intention of future land use decisions and current perceptions (Testing Hypothesis 4)}

Regarding the relationship between perception of corn and soybean area and future land conversion intention from grass to crop, we first combine the two decreasing categories with the "within 5\%" category. Among the three resulting categories, Hypothesis $\mathrm{H} 4$ conjectures that those who perceived a higher increase in corn and soybean area are also more likely to intend grass to cropland conversion in the next 10 years. Results in Appendix Table A2 are consistent 
with this conjecture.

Table 4 provides estimation results on Hypothesis H4, where it is shown that overperception implies higher likelihood of future conversion. We estimate equation (4) with three different variations from most parsimonious to most complex. Model 1 shows that perception bias significantly increases the odds that future conversion is intended. Model 2 includes more control variables and the perception bias becomes less significant. It ceases to be significant in Model 3. Previous conversion experience, instead, has significant and larger impacts on future conversion experience, as it increases the odds of future conversion to over 2.6 times that without past conversion based on Model 2 and 3. Off-farm employment status also plays a significant role; those who are less involved with farming appear to be more likely to intend future conversions to cropland. Not surprisingly, land quality (land class I to III) increases the odds of future conversion to cropland. In addition, survey respondents indicate that future conversions are more likely in areas with more grassland locally (this effect is statistically significant) and less likely to occur in areas where CropScape identified higher percentage increase in corn and soybean area during 2006-2015 (this effect is not statistically significant). A likely explanation is that there is less suitable land left for conversion in areas where CDL indicates significant conversions has already occurred. To the contrary, respondents were likely to intend to convert more grassland to corn and soybean production in areas with more grassland. Longitude, too, has a significant positive impact on future conversion to cropland. It seems that the focus of land use conversion will gradually shift to the west as most of the land in the east has already been converted.

\section{An alternative explanation of perception biases}

Thus far, our empirical data reveal that there was systematic bias in perceived land use changes. We also found evidence that a preference for choice validation through perceived confirmatory actions by others could potentially be an explanation for the bias. Admittedly, there could be 
other plausible explanations for such apparent bias. For example, farmers who are very concerned about grassland losses might also over-perceive the extent of corn and soybean expansion in their local regions due to their worry over loss of grassland. It is beyond the scope of our data to test for the validity of such reasoning. However, we offer another explanation below, that is consistent with our survey data and that is related to the perceived main drivers of land use changes regarding own decisions and the decision of those in one's own locality.

In our study, we asked respondents about factors that motivated land use change over the previous ten years within 5 miles of their operation base. With the exception of land units at issue, the queries were structured exactly the same as for own-farm land use. Specifically, the questions are: "How much impact has each of the following farm-related issues had on changing agricultural land use in your local area during the past 10 years?" and "How much impact has each of the following farm-related issues had on changes you have made in the way you use your agricultural land?" Summary statistics are available in Table A3. ${ }^{7}$ All eight market and technology factors (including crop and input prices, crop insurance policies, and improved crop yields, etc.) were ranked lower in importance in individual's land use decisions than the importance in local land use changes. For example, for the factor "Changing crop prices," the ranking of impacts on own land use decision averaged 2.19, compared to 2.75 for ranking of impacts on local land use changes. For "improving wildlife habitat," the reverse is true; that is, the ranking value for own decision (1.42) is larger than the ranking value for local land use changes (1.33). For changing climate patterns, the difference between one's own land and local area is not significant.

One rationale for these differences is that, not knowing the specific context about their neighbors' land use decisions, a farmer may only ascribe common economic motives to their neighbors' actions but see more complexity and nuance in their own motives. For example, land stewardship, wildlife, family circumstances and legacy concerns may loom large in an 
individual's decisions but tend to be ignored when considering others' land use decisions. As explained earlier, economic conditions were favorable in our study period for conversion from grassland to cropland. If farmers believe that others in their locality have been more responsive to favorable market conditions and thus converted grassland in response, then it is reasonable that we observe over-perception of cropland area. This is consistent with the "better-thanaverage" psychological effects (Bergquist 2020; Leviston and Uren 2020), whereby each individual farmer believes that others in her locality are less concerned than herself about environmental stewardship and family legacy and so are more willing to convert their grassland when crop prices are high. Such a tendency may lead to the perception that there is more conversion of grassland than there actually is.

\section{Concluding remarks: land use, perceptions changes and information policy}

A critical aspect in our understanding of the drivers underlying land use changes is the human dimensions of these changes, of which farmer characteristics and regional land use patterns are central. In the existing literature, this human dimension is mostly reflected in economic motives; there has been little study of behavioral and psychological factors that may also influence land use changes. It is increasingly recognized that research on perceptions can inform courses of action to improve the effectiveness of conservation efforts (Bennett, 2006). In this work, we study how farmers' perceptions about land use changes are related to actual changes. We argue that, to the extent that a farmer's perceptions about land use changes emerge from complex personal experience and from local context, these perceptions may be inaccurate and most important of all, different farmers may differ systematically in how they form perceptions. Farmers may 'see' more changes because that is what they would like to see. Our data analysis finds evidence in support of over-perceptions about expansion in cropland acres, and also evidence that the over-perceptions are associated with past land use decisions.

The current set of policies addressing grassland conservation mostly involve offering 
economic incentives or disincentives for land conversion. While it is beyond the scope of our paper and data to examine how over-perceptions affect the outcomes of conservation programs, our findings imply that the current conservation toolkit could be expanded by considering the likely impacts of misperceptions. Given the apparent evidence of perception biases regarding land use changes and its connection to past land use decisions, it would be tempting to identify policy opportunities that seek to manage perceptions. However, as outlined in our literature review, the formation of perceptions is a complex process as perceptions are not exogenous to the context. Putative cognitive errors imply that increasing factual information availability and learning will not necessarily induce complete adjustment of views on these facts (Rabin, 1998). As Akerlof and Dickens (1982) pointed out, the underlying assumption for misperception is not that people are basically misinformed- -if they believe something other than the truth, they do so by their own choice." This is not to say that misperceptions cannot be changed, it just highlights that the process of changing misperceptions is much more complex than simply making facts available (Carey et al., 2020; Nyhan 2020).

For sound policy design, making accurate local land use data more readily available needs to be combined with other elements. One such element could be managing personal internalities (see, e.g., Gabaix 2018) which will require a more comprehensive understanding of the factors contributing to perception biases and land use decisions. If over-perception of cropland area arises, at least in part, from the "motivated belief" that conversion from grass to crop is a good choice, then, besides land use data, accurate information on the benefits and costs of land conversion might help mitigate misperception even though such data does not directly tackle perception biases. Following this logic, in order to generate greater impacts, some conservation funding could be allocated for recording, estimating and disseminating itemized costs of plowing up grassland and preparing it for cropping (e.g., herbicide application, installation of drainage or irrigation system, labor and equipment requirement), and realistic crop yields on 
converted land. Doidge et al. (2020) established two results pertinent to our analysis. One was that had increasing profit been the dominant motive then more land would have been converted to crop production. The other was that stewardship motives, including social and cultural dimensions, were important factors in determining the land use choice. While it is doubtful that landowners and operators located in the region were unaware of these facts, comparative profit data are likely most readily available to them than are the particular viewpoints and circumstances that give rise to non-profit motives. Pointing out that a large number of their peers are motivated not to convert may affect their own views on the merits of conversion.

Any policy that is designed to address misperceptions will be bound to differ for different contexts. For example, what applies to perception biases related to risks, which has been well studied, will not necessarily apply to misperceptions related to land use changes. We suggest that a deeper understanding of how perceptions relate to actions is warranted before seeking to use information instruments as components in public land management strategy. While our study is only a first step towards such understanding, our findings imply that further research on land use changes will need to go beyond the standard assumption in economic analyses that land conversion decisions are determined by the expected monetary benefits and costs of conversion.

Acknowledgments: This work has been supported by the Elton R. Smith Endowment Fund at Michigan State University and by a grant from the National Institute of Food and Agriculture (NIFA) of the U.S. Department of Agriculture (USDA) (DUNS No. 005309844). We thank Larry Janssen and Mike Wimberly who worked closely with us on developing the survey as well as several kind growers and local experts who pilot-tested the instrument. Above all we thank the many farmers who responded to our survey. 


\section{References}

Adesina, A.A., and J. Baidu-Forson. 1995. "Farmers' perceptions and adoption of new agricultural technology: Evidence from analysis in Burkina Faso and Guinea, West Africa.” Agricultural Economics 13(1), 1-9.

Akerlof, G., and W.T. Dickens. 1982. "The economic consequences of cognitive dissonance." American Economic Review 72 (3), 307-19.

Alesina, A., S. Stantcheva, and E. Teso. 2018. "Intergenerational Mobility and Preferences for Redistribution." American Economic Review 108(2): 521-554.

Allcott, H. 2011. "Consumers' Perceptions and Misperceptions of Energy Costs." American Economic Review, 101 (3), 98-104. DOI: 10.1257/aer.101.3.98

Arbuckle, G.J., L.W. Morton, and J. Hobbs. 2013. "Farmer beliefs and concerns about climate change and attitudes toward adaptation and mitigation: Evidence from Iowa." Climatic Change 118(3), 551-563.

Arbuckle, J. Gordon, and G. Roesch-McNally. 2015. "Cover crop adoption in Iowa: The role of perceived practice characteristics." Journal of Soil and Water Conservation 70 (6): 418-429.

Arora, G., Wolter, P.T. 2018. Tracking land cover change along the western edge of the U.S. Corn Belt from 1984 through 2016 using satellite sensor data: Observed trends and contributing factors. Journal of Land Use Science 13 (1-2), 1-22.

Arora, G., H. Feng, D.A. Hennessy, C.R. Loesch, S. Kvas. 2021. "The impact of production network economies on spatially-contiguous conservation- Theoretical model with evidence from the U.S. Prairie Pothole Region.” Journal of Environmental Economics \& Management, 107, https://doi.org/10.1016/j.jeem.2021.102442.

Balcetis, E., \& Dunning, D. (2006). See what you want to see: Motivational influences on visual perception. Journal of Personality \& Social Psychology, 91(4), 612-625.

https://doi.org/10.1037/0022-3514.91.4.612.

Bénabou, R. 2012. “Groupthink: Collective delusions in organizations and markets.” Review of Economic Studies 80(2), 429-462.

Bénabou, R. 2015. “The economics of motivated beliefs.” Revue d'Économie Politique 125, 665-685.

Bénabou, R. and J. Tirole. 2016. "Mindful Economics: The Production, Consumption, and Value of Beliefs." Journal of Economic Perspectives 30(3), 141-164. 
Bennett, N.J. (2016), Using perceptions as evidence to improve conservation and environmental management. Conservation Biology, 30: 582-592. https://doi.org/10.1111/cobi.12681

Bergquist, M. 2020. "Most People Think They Are More Pro-Environmental than Others: A Demonstration of the Better-than-Average Effect in Perceived Pro-Environmental Behavioral Engagement." Basic \& Applied Social Psychology, 42:1, 50-61, DOI: 10.1080/01973533.2019.1689364

Botzen, W.J.W, H. Kunreuther, and E. Michel-Kerjan. 2015. "Divergence between individual perceptions and objective indicators of tail risks: Evidence from floodplain residents in New York City.” Judgment \& Decision Making 10(4), 365-385.

Brown, D.G., C. Polsky, P. Bolstad, S.D. Brody, D. Hulse, R. Kroh, T.R. Loveland, and A. Thomson. 2014. Ch. 13: Land Use and Land Cover Change. Climate Change Impacts in the United States: The Third National Climate Assessment, J. M. Melillo, Terese (T.C.) Richmond, and G. W. Yohe, Eds., U.S. Global Change Research Program, 318-332. doi:10.7930/J05Q4T1Q.

Carey, J.M., V. Chi, D. J. Flynn, B. Nyhan, T. Zeitzoff. 2020. "The effects of corrective information about disease epidemics and outbreaks: Evidence from Zika and yellow fever in Brazil." Science Advances 6(5), eaaw7449. DOI: 10.1126/sciadv.aaw7449.

Coibion, O., Y. Gorodnickenko, and R. Kamdar. 2018. "The formation of expectations, inflation, and the Phillips curve." Journal of Economic Literature 56(4), 1447-1491.

Conley, T.G., and C.R. Udry. 2010. "Learning about a new technology: Pineapples in Ghana." American Economic Review 100(1), 35-69.

Doidge, M., D.A. Hennessy, and H. Feng. 2020. "The role of economic returns in land use change: Evidence from farm-level data in the US Northern Great Plains." Journal of Soil \& Water Conservation 75(5) 669-679; DOI: https://doi.org/10.2489/jswc.2020.00084

Dramstad, W.E., M. Sundli Tveit, W.J. Fjellstad, and G.L.A. Fry. 2006. "Relationships between visual landscape preferences and map-based indicators of landscape structure." Landscape \& Urban Planning 78(4), 465-474.

Feng, H., D.A. Hennessy, and R. Miao. 2013. "The effects of government payments on cropland acreage, Conservation Reserve Program enrollment, and grassland conversion in the Dakotas." American Journal of Agricultural Economics 95(2), 412-418.

Friesenbichler, K.S., E. Selenko, and G. Clarke. 2018. "Perceptions of corruption: An empirical 
study controlling for survey bias." Journal of Interdisciplinary Research 30(1), 55-77.

Fryer, R.G., P. Harms, and M.O. Jackson. 2019. "Updating Beliefs when Evidence is Open to Interpretation: Implications for Bias and Polarization." Journal of the European Economic Association, 17(5), 1470-1501.

Gabaix, X. 2019. "Behavioral inattention.” In: B. Douglas Bernheim, B.D., DellaVigna, S., and D. Laibson (Eds.), Handbook of Behavioral Economics - Foundations and Applications 2, Vol. 2, Elsevier.

Georganas, S., P.J. Healy, and N. Li. 2014. "Frequency bias in consumers' perceptions of Inflation: An experimental study." European Economic Review 67(April), 144-158.

Green, T.R., H. Kipka, O. David, and G.S. McMaster. 2018. "Where is the Corn Belt, and how is it changing?" Science of the Total Environment 618(March 15), 1613-1618.

Hao, L., and D. Houser. 2017. "Perceptions, intentions and cheating." Journal of Economic Behavior \& Organization 133, 52-73.

Harrell, F.E. 2015. “Ordinal logistic regression.” In F.E. Harrell (Ed.), pp. 311-325, Ch. 13, Regression Modeling Strategies. Springer, doi.org/10.1007/978-3-319-19425-7_13.

Helms, D. 1992. "The development of the Land Capability Classification." In D. Helms (Ed.), pp. 60-73, Readings in the History of the Soil Conservation Service. Washington, DC: Soil Conservation Service. http://www.nrcs.usda.gov/Internet/FSE_DOCUMENTS/stelprdb1043484.pdf

Kalivoda, O., J. Vojar, Z. Skrivanova, and D. Zahradnik. 2014. "Consensus in landscape preference judgments: The effects of landscape visual aesthetic quality and respondents' characteristics." Journal of Environmental Management 137(May), 36-74.

Kaufman, J., J.C. Tarasuik, L. Dafner, J. Russell, S. Marshall, and D. Meyer. 2013. "Parental misperception of youngest child size." Current Biology 23(24), R1085-R1086.

Kline, K.L., N. Singh, and V.H. Dale. 2013. "Cultivated hay and fallow/idle cropland donfound analysis of grassland conversion in the Western Corn Belt." PNAS USA 110(31), E2863.

Kraay, A., and P. Murrell. 2016. "Misunderestimating corruption." Review of Economics \& Statistics 98(3), 455-466.

Laingen, C. 2015. "Measuring cropland change: A cautionary tale." Papers in Applied Geography 1(1), 65-72.

Lark, T.J., J.M. Salmon, and H.K. Gibbs. 2015. "Cropland expansion outpaces agricultural and 
biofuel policies in the United States." Environmental Research Letters 10(4), No.: 044003.

Lark, T.J., R.M. Mueller, D.M. Johnson, and H.K. Gibbs. 2017. "Measuring land-use and landcover change using the U.S. Department of Agriculture's cropland data layer: Cautions and recommendations." International Journal of Applied Earth Observation \& Geoinformation 62(October), 224-235.

Lark, T.J.; I.H., Schelly, H.K. Gibbs. 2021. "Accuracy, Bias, and Improvements in Mapping Crops and Cropland across the United States Using the USDA Cropland Data Layer." Remote Sensing 13(5), 968 https://doi.org/10.3390/rs13050968.

Leviston, Z., and H.V. Uren. 2020. “Overestimating one's 'green' behavior: Better-than-average bias may function to reduce perceived personal threat from climate change." Journal of Social Issues 76(1), 70-85.

Lu, C., Z. Yu, H. Tian, D.A. Hennessy, H. Feng, M. Al-Kaisi, Y. Zhou, T. Sauer, R. Arritt. 2019. "Increasing carbon footprint of grain crop production in the U.S. Western Corn Belt." Environmental Research Letters 13, 124007. http://iopscience.iop.org/article/10.1088/17489326/aae9fe.

Matsumoto, M., and F. Spence. 2016. "Price beliefs and experience: Do consumers' beliefs converge to empirical distributions with repeated purchases?" Journal of Economic Behavior \& Organization 126, 243-254.

Merrill, R.M., and J.S. Richardson. 2009. "Validity of self-reported height, weight, and body mass index: Findings from the National Health and Nutrition Examination Survey, 20012006." Preventing Chronic Disease 6(4), A121.

Miao, R., D.A. Hennessy, and H. Feng. 2014. "Sodbusting, crop insurance, and sunk conversion costs." Land Economics 90(4), 601-622.

Nyhan, B. 2020. "Facts and Myths about Misperceptions." Journal of Economic Perspectives, 34(3), 220-36. DOI: 10.1257/jep.34.3.220

Olken, B.A. 2009. "Corruption perceptions vs. corruption reality." Journal of Public Economics 93(7-8), 950-964.

Olofsson, P., G.M. Foody, S.V. Stehman, C.E. Woodcock. 2013. "Making better use of accuracy data in land change studies: Estimating accuracy and area and quantifying uncertainty using stratified estimation." Remote Sensing of Environment 129, 122-131.

Otto, C.R.V., C.L. Roth, B.L. Carlson, and M.D. Smart. 2016. "Land-use change reduces 
habitat suitability for supporting managed honey bee colonies in the Northern Great Plains." PNAS USA 113(37), 10430-10435.

Pates, N.J., and N.P. Hendricks. 2021. "Fields from Afar: Evidence of Heterogeneity in United States Corn Rotational Response from Remote Sensing Data." American Journal of Agricultural Economics. https://doi.org/10.1111/ajae.12208.

Plantinga, A.J. 1996. "The Effect of Agricultural Policies on Land Use and Environmental Quality." American Journal of Agricultural Economics 78(4), 1082-1091.

Poston, W.S.C., N. Jitnarin, C.K. Haddock, S.A. Jahnke, and R.S. Day. 2014. "Accuracy of self-reported weight, height and BMI in U.S. firefighters.” Occupational Medicine 64(4), 246-254.

Proto, E., and D. Sgroi. 2017. "Biased beliefs and imperfect information." Journal of Economic Behavior \& Organization 136(April), 186-202.

Rabin, M. 1998. "Psychology and Economics." Journal of Economic Literature, 36 (1), 11-46.

Rabin, M. and J.L. Schrag. 1999. "First Impressions Matter: A Model of Confirmatory Bias." The Quarterly Journal of Economics 114(1), 37-82.

Rashford, B.S., J.A. Walker, and C.T. Bastian. 2011. "Economics of grassland conversion to cropland in the Prairie Pothole Region." Conservation Biology 25(2), 276-284.

Reitsma, K.D., B.H. Dunn, U. Mishra, S.A. Clay, T. DeSutter, and D.E. Clay. 2015. "Land use change impact on soil sustainability in a climate and vegetation transition zone." Agronomy Journal 107(6), 2363-2372.

Richardson, L. 2009. "Statement Before the Senate Committee on Commerce, Science and Transportation Field Hearing on: Addressing Surface Transportation Needs in Rural America." (accessed 2020 April)

https://www.commerce.senate.gov/services/files/378F76EB-6084-40C4-8CF7BBA34A154E16.

Saponara, N. 2018. "Bayesian optimism.” Economic Theory 66(2), 375-406.

Tirole, J. 2002. "Rational irrationality: Some economics of self-management." European Economic Review 46(4-5), 633-655.

Tversky, A. and D. Kahneman. 1974. "Judgment under Uncertainty: Heuristics and Biases." Science, 27 Sep: 1124-1131.

U.S. Government Accountability Office (USGAO). 2007. Agricultural Conservation: Farm 
Program Payments Are an Important Factor in Landowners' Decisions to Convert Grassland to Cropland. Washington, D.C., Report 07-1054, September, 70 pages.

USDA National Agricultural Statistics Service (USDA-NASS). 2021a. Cropscape-Cropland

Data Layer. https://nassgeodata.gmu.edu/CropScape/. (Accessed in April.)

-2021b. CropScape and Cropland Data Layer Metadata. (Accessed in April.)

https://www.nass.usda.gov/Research and Science/Cropland/metadata/meta.php.

USDA Natural Resources Conservation Service (USDA-NRCS). 2021. The National Resources

Inventory. (Accessed in January.)

https://www.nrcs.usda.gov/wps/portal/nrcs/main/national/technical/nra/nri/

Walker, J., J.J. Rotella, C.R. Loesch, R.W. Renner, J.K. Ringelman, M.S. Lindberg, R. Dell, and K.E. Doherty. 2013. "An integrated strategy for grassland easement acquisition in the Prairie Pothole Region, USA.” Journal of Fish \& Wildlife Management 4(2), 267-279.

Wang, X., B.G. McConkey, A.J. VandenBygaart, J. Fan, A. Iwaasa, and M. Schellenberg. 2017. "Grazing improves C and N cycling in the Northern Great Plains: a meta-analysis."

Scientific Reports 6, 33190, doi: 10.1038/srep33190227-237.

Wang, T., M. Luri, L. Janssen, D.A. Hennessy, H. Feng, M. Wimberly, and G. Arora. 2017. "Determinants of motives for land use decisions at the margins of the Corn Belt." Ecological Economics 134, 227-237.

Wang, T., A. Ayesh, D.A. Hennessy, and H. Feng. 2018. "Cropland reflux: Trends in and locations of land use change in the Dakotas, 2007 to 2012 and 2012 to 2017." Bulletin 274938, South Dakota State University, Agricultural Experiment Station, July.

Wang, Y., M.S. Delgado, J. Sesmero, and B.M. Gramig. 2020. "Market Structure and the Local Effects of Ethanol Expansion on Land Allocation: A Spatially Explicit Analysis.” First published: 10 August, https://doi.org/10.1111/ajae.12119.

Wimberly, M.C., L.L. Janssen, D.A. Hennessy, M. Luri, N.M. Chowdhury, H. Feng “Cropland expansion and grassland loss in the eastern Dakotas: New insights from a farm-level survey." Land Use Policy 63(April), 160-173.

Wooldridge, J.M. 2010. Econometric Analysis of Cross Section and Panel Data. MIT press. Wright, C.K., and M.C. Wimberly. 2013. "Recent land use change in the Western Corn Belt threatens grasslands and wetlands." PNAS USA 110(10), 4134-4139.

Ziebarth, N.R. 2018. "Lung cancer risk perceptions.” Preventive Medicine 110(May), 16-23. 
Figure 1. An illustration of the impacts of crop prices on land conversion incentives - as crop prices increase, land with an index value between $\hat{\theta}$ and $\theta^{*}$ will become more suitable for crop production, that is, generating a higher net return in crop than in grass.

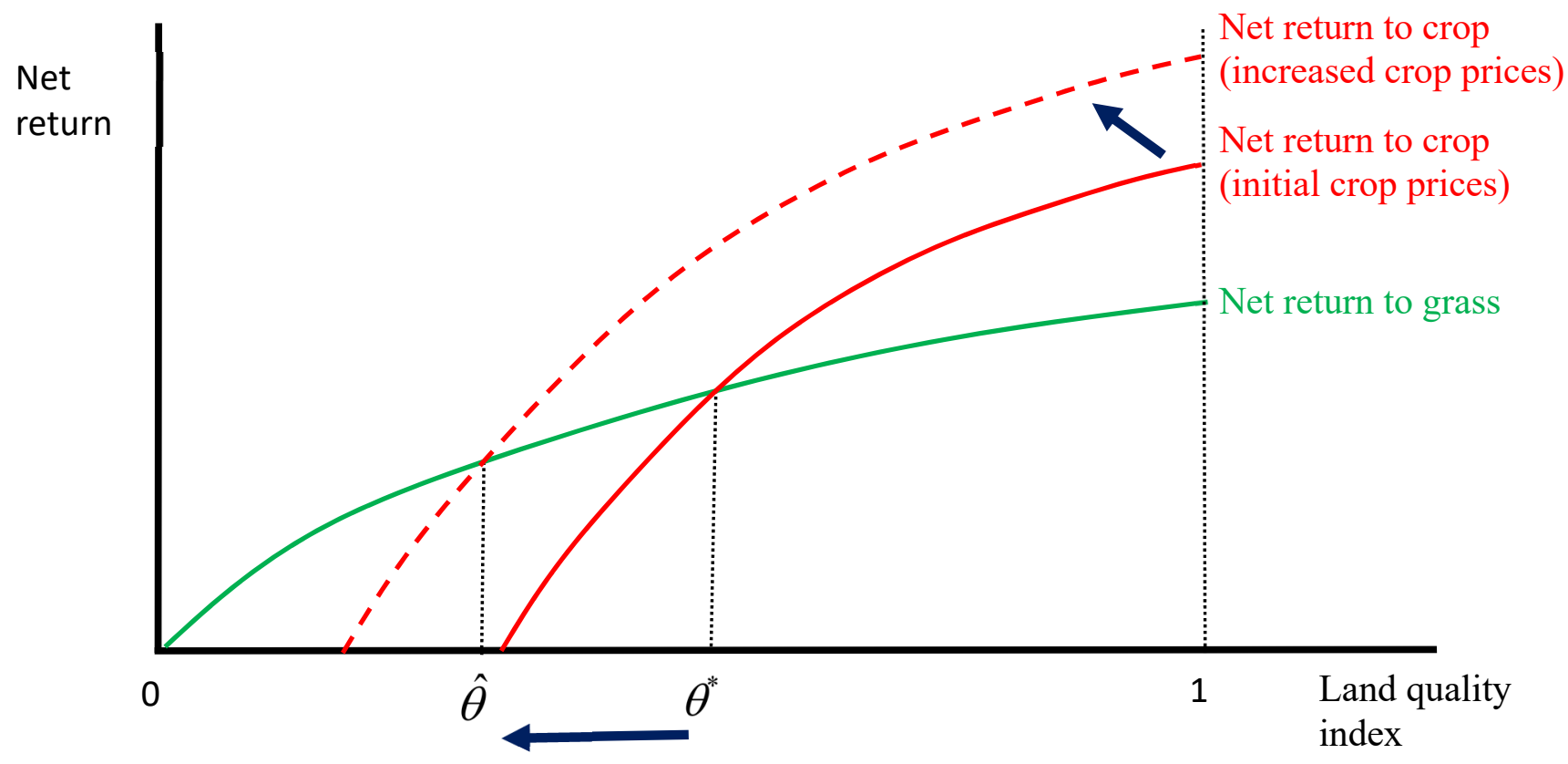

Figure 2. Cropland share of a respondent's acres and the number of respondents in counties.

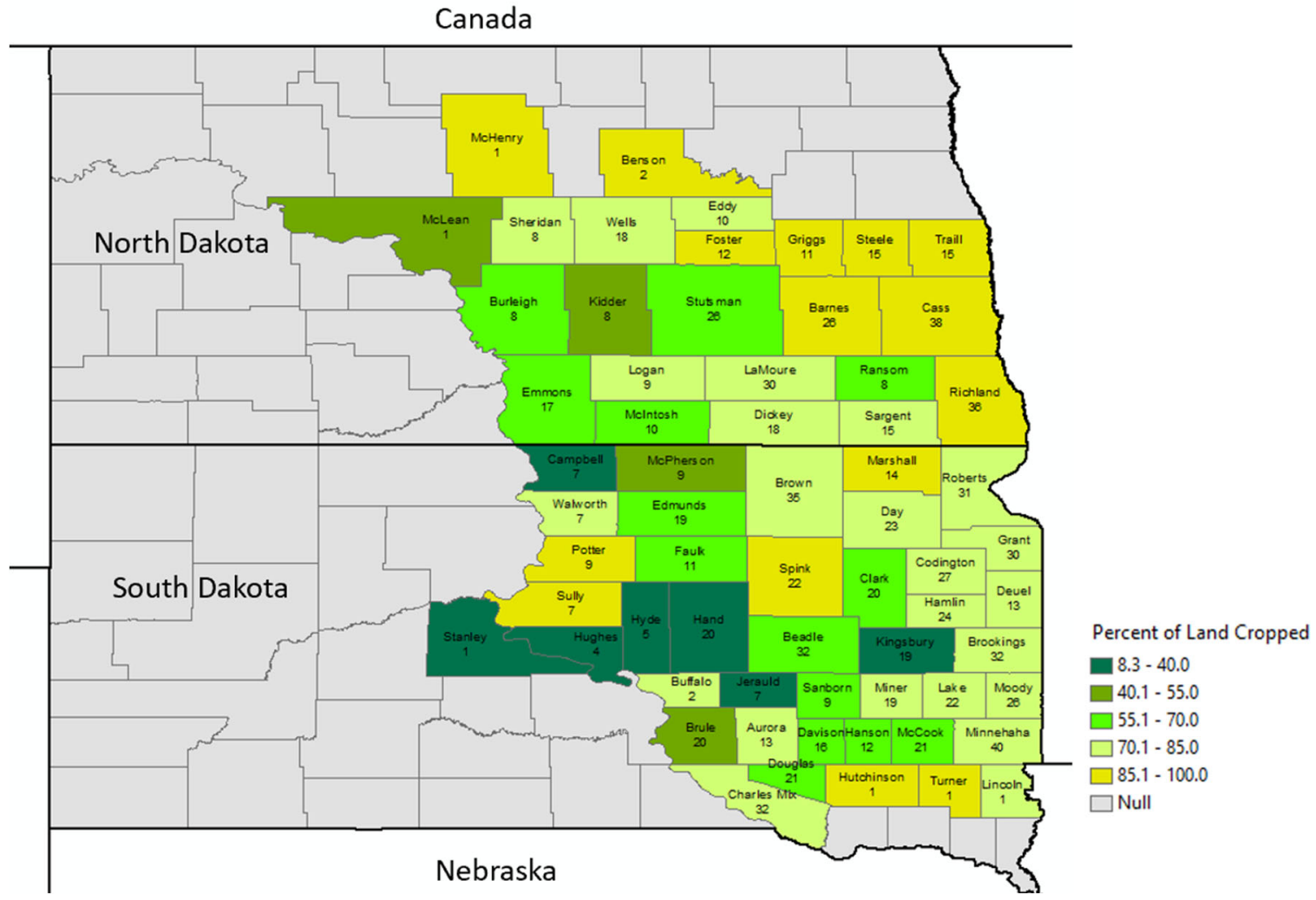


Table 1. Summary statistics of key variables.

\begin{tabular}{lrrrrr}
\hline Variable & $N$ & Mean & Std. Dev. & Min. & Max. \\
\hline Farm size (acres operated) & 996 & 1,686 & 1,937 & 18 & 27,000 \\
Cropland acres & 972 & 1,226 & 1,448 & 0 & 19,023 \\
Farmer's age* & 1,017 & 3.303 & 1.084 & 1 & 5 \\
Land tenure indicator* & 1,001 & 2.752 & 1.220 & 1 & 5 \\
Off-farm employment* & 1,026 & 1.235 & 0.701 & 1 & 5 \\
Latitude & 1,025 & 45.273 & 1.288 & 42.9 & 47.83 \\
Longitude & 1,025 & 98.023 & 1.043 & 96.5 & 100.79 \\
Percent of land in land class III or better & 1,025 & 92.683 & 13.90 & 0.02 & 100 \\
Distance to ethanol plants & 997 & 43.13 & 35.17 & 1.00 & 200.00 \\
\% change in corn and soybean acres, & 1,008 & 4.307 & 0.802 & 1 & 5 \\
perception* & & & & & \\
Change in infrastructure for corn, perception* & 1,002 & 3.827 & 0.879 & 1 & 5 \\
\% change in corn and soybean acres, CropScape & 1,025 & 3.141 & 2.875 & -1.60 & 16.65 \\
\% of grassland acres, 5 mi. radius, NLCD & 937 & 7.67 & 14.69 & 0 & 79.3 \\
\% of land in classes I-III, 5 mi. radius & 1,025 & 92.68 & 13.90 & 0.020 & 100 \\
\% of land with slope $\leq 3$ degrees, 5 mi. radius & 1,025 & 47.80 & 37.26 & 0 & 100 \\
Conversion to cropland, past 10 years & 1,026 & 0.242 & 0.428 & 0 & 1 \\
Intended conversion to cropland, next 10 years & 809 & 0.158 & 0.365 & 0 & 1 \\
Intended conversion to grassland, next 10 years & 872 & 0.095 & 0.294 & 0 & 1 \\
\hline
\end{tabular}

*Note: These variables are category variables. Categorical data descriptions are provided as follows:

-For farmer's age, coding is ' 19 to 34 ' $=$ ' 1 ', ' 35 to 49 ' $=$ ' 2 ', ' 50 to 59 ' $=$ ' 3 ', ' 60 to 69 ' $=$ ' 4 ' and ' 70 or over' $=$ ' 5 '.

-For tenure status, 'own all operated acres' = ' 1 ', 'own most operated acres' = '2', 'own about half of operated acres' $=$ ' 3 ', 'rent most operated acres' $=$ '4' and 'rent all operated acres' $=$ ' 5 '.

-For farmers' principal occupation, 'farming or ranching, = ' 1 ', 'employment in off-farm job' = ' 2 ', 'own/operate a non-farm business' $=$ ' 3 ', 'retired' $=$ ' 4 ' and 'other' $=$ ' 5 '.

-For change in corn and soybean acres, perception: 'decreased markedly (over 10\%)' = ' 1 ', 'decreased somewhat (5-10\%)' = '2', 'stayed about the same (less than 5\%)' = ' 3 ', 'increased somewhat $(5-10 \%)$ ' $=$ ' 4 ' and 'increased markedly (over 10\%)' $=$ ' 5 '.

-For change in infrastructure for corn, perception: 'much worse' = ' 1 ', 'somewhat worse' = ' 2 ', 'stayed about the same' $=$ ' 3 ', 'somewhat better' $=$ '4', 'much better' $=$ ' 5 '. 
Table 2. Number of respondents in different categories of perceived cropland changes and actual changes as measured by CropScape data, within five-mile radius of a respondent's address.

\begin{tabular}{|c|c|c|c|c|c|c|c|}
\hline & \multicolumn{5}{|c|}{ CropScape } & \multirow[b]{2}{*}{$\begin{array}{l}\text { Row } \\
\text { sum }\end{array}$} \\
\hline & & $\begin{array}{l}\text { Decreased } \\
\text { by }>10 \%\end{array}$ & $\begin{array}{l}\text { Decreased } \\
\text { by } 5-10 \%\end{array}$ & $\begin{array}{l}\text { Within } \\
5 \%\end{array}$ & $\begin{array}{l}\text { Increased } \\
\text { by } 5-10 \%\end{array}$ & $\begin{array}{l}\text { Increased } \\
\text { by }>10 \%\end{array}$ & \\
\hline \multirow{6}{*}{$\stackrel{\overrightarrow{0}}{\stackrel{\vec{n}}{\Xi}}$} & $\begin{array}{l}\text { Decreased by }> \\
10 \%\end{array}$ & 0 & 0 & 4 & 2 & 0 & $\underline{6}$ \\
\hline & $\begin{array}{l}\text { Decreased by } \\
5-10 \%\end{array}$ & 0 & 0 & 6 & 2 & 0 & $\underline{8}$ \\
\hline & Within 5\% & 0 & 0 & 127 & 27 & 3 & $\underline{157}$ \\
\hline & $\begin{array}{l}\text { Increased by } 5- \\
10 \%\end{array}$ & 0 & 0 & 269 & 67 & 1 & 337 \\
\hline & $\begin{array}{l}\text { Increased by }> \\
10 \%\end{array}$ & $\mathbf{0}$ & $\mathbf{0}$ & 358 & 120 & 21 & $\underline{499}$ \\
\hline & Column sum & $\underline{0}$ & $\underline{0}$ & $\underline{764}$ & $\underline{218}$ & $\underline{25}$ & $\underline{1,007}$ \\
\hline
\end{tabular}

Table 3. Estimations of perception as function of past land use decisions and other variables as given in Logit model, equation (3). (Dependent variable is odds of choosing higher change category. The estimation results in this table are the exponential value of the coefficients in equation (3). Alternative models incorporate different variables. Model 3 and Model 4 differ in the ending year used to calculate cropland \% change: Model 3 uses 2014 value as the ending year while Model 4 uses the average of values in 2013, 2014 and 2015.)

3a. Perceptions about the extent of changes in cropland area

\begin{tabular}{|c|c|c|c|c|}
\hline Parameters & Model 1 & Model 2 & Model 3 & Model 4 \\
\hline Conversion from grass to crop & $1.650^{c}$ & $1.598^{c}$ & $1.622^{c}$ & $1.618^{c}$ \\
\hline Farm acre & & 1.009 & $0.937^{\mathrm{a}}$ & $0.938^{a}$ \\
\hline Years operating & & 0.969 & 0.976 & 0.975 \\
\hline Tenure index & & $1.174^{\mathrm{c}}$ & $1.207^{\mathrm{c}}$ & $1.204^{c}$ \\
\hline Education & & 1.113 & 1.040 & 1.041 \\
\hline Off-farm employment & & 1.034 & 1.016 & 1.017 \\
\hline CropScape cropland $\%$ change & & & $1.049^{\mathrm{a}}$ & 1.045 \\
\hline NCLD \% grassland, 2006, 5 mi. radius & & & 0.998 & 0.999 \\
\hline$\%$ land in classes I-III, 5 mi. radius & & & $1.009^{\mathrm{a}}$ & $1.009^{a}$ \\
\hline$\%$ land with slope $\leq 3,5$ mi. radius & & & 1.000 & 1.000 \\
\hline Latitude & & & $1.636^{\mathrm{c}}$ & $1.630^{c}$ \\
\hline Longitude & & & $1.208^{\mathrm{b}}$ & $1.211^{\mathrm{b}}$ \\
\hline Percent Concordant & $29.1 \%$ & $58.2 \%$ & $68.8 \%$ & $68.7 \%$ \\
\hline
\end{tabular}


3b. Perceptions about the extent of infrastructure change in corn production

\begin{tabular}{lrrrr}
\hline Parameters & Model 1 & Model 2 & Model 3 & Model 4 \\
\hline Conversion from grass to crop & $1.651^{\mathrm{c}}$ & $1.609^{\mathrm{c}}$ & $1.650^{\mathrm{c}}$ & $1.650^{\mathrm{c}}$ \\
\hline Farm acre & & 1.056 & 1.045 & 1.045 \\
Years operating & & $0.885^{\mathrm{a}}$ & $0.874^{\mathrm{a}}$ & $0.873^{\mathrm{a}}$ \\
Tenure index & & 1.095 & 1.077 & 1.076 \\
Education & & 1.076 & 1.006 & 1.006 \\
Off-farm employment & 1.068 & 1.060 & 1.060 \\
\hline CropScape cropland \% change & & 1.008 & 1.007 \\
$N L C D \%$ grassland, 2006, 5 mi. radius & & & 0.999 & 0.999 \\
\% land in classes I-III, 5 mi. radius & & 1.002 & 1.002 \\
\% land with slope $\leq 3,5$ mi. radius & & & 1.003 & 1.003 \\
Latitude & & & $1.172^{\mathrm{c}}$ & $1.171^{\mathrm{c}}$ \\
Longitude & & & $0.995^{\mathrm{a}}$ & $0.995^{\mathrm{a}}$ \\
Distance to ethanol plants & & & $61.1 \%$ & $61.1 \%$ \\
\hline Percent Concordant & & & & \\
\hline
\end{tabular}

Note for Table 3a and 3b: For all estimation results, superscripts "a", "b", "c" mean statistically significant at $10 \%, 5 \%$, and $1 \%$, respectively.

Table 4. Estimation results of intended future land use changes as function of current perception bias and other variables from logistic model in equation (4).

\begin{tabular}{lrrr}
\hline Parameters & Model 1 & Model 2 & Model 3 \\
\hline Perception bias in cropland area change & $1.037^{\mathrm{c}}$ & $1.040^{\mathrm{a}}$ & 1.036 \\
Conversion from grass to crop & & $2.841^{\mathrm{c}}$ & $2.626^{\mathrm{c}}$ \\
Farm acre & & 1.061 & 1.011 \\
Years operating & & 0.832 & 0.889 \\
Tenure index & $0.795^{\mathrm{a}}$ & 0.848 \\
Education & 1.011 & 1.083 \\
Off-farm employment & $1.389^{\mathrm{a}}$ & $1.488^{\mathrm{b}}$ \\
\hline CropScape cropland \% change & & 0.951 \\
NLCD \% grassland, 2006, 5 mi. radius & & $1.019^{\mathrm{a}}$ \\
\% land in classes I-III, 5 mi. radius & & $1.023^{\mathrm{a}}$ \\
\% land with slope $\leq 3,5$ mi. radius & & 1.000 \\
Latitude & & & 0.853 \\
Longitude & & & $1.679^{\mathrm{c}}$ \\
\hline Percent Concordant & $56.2 \%$ & $69.8 \%$ & $75 \%$ \\
\hline
\end{tabular}

Note: For all estimation results, superscripts "a", "b", "c" mean statistically significant at 10\%, $5 \%$, and $1 \%$, respectively. 


\section{Appendix: Additional Tables}

Table A1a. The number of respondents by past conversion history and categories of perceived change in cropland area

Perceived change in cropland area

\begin{tabular}{lrrrrrr}
\hline & $\begin{array}{r}>10 \% \\
\text { Conversion from grass to crop }\end{array}$ & $\begin{array}{r}5-10 \% \\
\text { decrease }\end{array}$ & $\begin{array}{r}5-10 \% \\
\text { decrease }\end{array}$ & Within 5\% & $\begin{array}{r}>10 \% \\
\text { increase }\end{array}$ & Total \\
increase
\end{tabular}

Table A1b. The number of respondents by past conversion history and categories of perceived infrastructure change in corn production

\begin{tabular}{lrrrrrr}
\hline & \multicolumn{7}{c}{ Perceived infrastructure change in corn production } \\
\hline & \multicolumn{2}{c}{ Much Somewhat Stayed about } & $\begin{array}{r}\text { Somewhat } \\
\text { Conversion from grass to crop }\end{array}$ & much & Total \\
worse & worse & the same & better & better \\
\hline 0 (No)-Number & 9 & 35 & 237 & 307 & 169 & 757 \\
0 (No)-Percentage in total & $1.2 \%$ & $4.6 \%$ & $31.3 \%$ & $40.6 \%$ & $22.3 \%$ & $100 \%$ \\
\hline 1 (Yes)-Number & 2 & 9 & 53 & 112 & 69 & 245 \\
1 (Yes)-Percentage in total & $0.8 \%$ & $3.7 \%$ & $21.6 \%$ & $45.7 \%$ & $28.2 \%$ & $100 \%$ \\
\hline
\end{tabular}


Table A2. The number of respondents by perception and intention to convert from grass to crop in the future

\begin{tabular}{lrrrc}
\hline & \multicolumn{4}{c}{ Intention to convert from grass to crop } \\
\hline Perceived change in cropland area & 0 (No) & 1 (Yes) & Total & Percent 'yes' \\
\hline Within $5 \%$ or decrease & 140 & 9 & 149 & $6.0 \%$ \\
Increased by $5-10 \%$ & 264 & 24 & 288 & $8.3 \%$ \\
Increased by $>10 \%$ & 376 & 49 & 425 & $11.5 \%$ \\
\hline Total & 780 & 82 & 862 & $9.5 \%$ \\
\hline
\end{tabular}


Table A3. Summary of the impact ranking of different factors in own land use decisions versus in neighborhood land use changes (The ranking ranges from 1 to 5 with 5 being "Great Impact" and 1 being "No Impact".)

\begin{tabular}{|c|c|c|c|c|c|c|c|}
\hline & \multirow[b]{2}{*}{ Variable } & \multicolumn{3}{|c|}{$\begin{array}{l}\text { Impact on agricultural } \\
\text { land use (own farm) }\end{array}$} & \multicolumn{3}{|c|}{$\begin{array}{l}\text { Impact on agricultural } \\
\text { land use (local area) }\end{array}$} \\
\hline & & $N$ & Mean & $\begin{array}{l}\text { Std. } \\
\text { Dev. }\end{array}$ & $N$ & Mean & $\begin{array}{l}\text { Std. } \\
\text { Dev. }\end{array}$ \\
\hline \multirow[t]{4}{*}{ Markets } & Changing crop prices & 1,010 & 2.190 & 0.839 & 791 & 2.747 & 0.520 \\
\hline & Changing input prices & 1,002 & 2.079 & 0.823 & 785 & 2.353 & 0.703 \\
\hline & $\begin{array}{l}\text { Availability of crop } \\
\text { insurance policies }\end{array}$ & 1,003 & 1.788 & 0.813 & 784 & 2.125 & 0.796 \\
\hline & $\begin{array}{l}\text { Labor availability } \\
\text { problems }\end{array}$ & 1,004 & 1.514 & 0.748 & 784 & 1.658 & 0.752 \\
\hline \multirow[t]{4}{*}{ Technology } & $\begin{array}{l}\text { Availability of drought- } \\
\text { tolerant seed }\end{array}$ & 1,004 & 1.606 & 0.763 & 785 & 1.781 & 0.760 \\
\hline & $\begin{array}{l}\text { Development in pest } \\
\text { management practices }\end{array}$ & 1,003 & 1.838 & 0.800 & 784 & 2.052 & 0.752 \\
\hline & Improved crop yields & 1,006 & 2.114 & 0.795 & 786 & 2.477 & 0.664 \\
\hline & $\begin{array}{l}\text { Development of } \\
\text { efficient cropping } \\
\text { equipment }\end{array}$ & 1,006 & 1.941 & 0.833 & 783 & 2.315 & 0.737 \\
\hline \multirow[t]{2}{*}{ Environmental } & $\begin{array}{l}\text { Improving wildlife } \\
\text { habitat }\end{array}$ & 1,002 & 1.416 & 0.657 & 781 & 1.329 & 0.578 \\
\hline & $\begin{array}{l}\text { Changing } \\
\text { weather/climate patterns }\end{array}$ & 1,007 & 1.766 & 0.810 & 783 & 1.849 & 0.790 \\
\hline
\end{tabular}

Note: All differences save one are significance at the $1 \%$ level. The difference for changing climate patterns is not significant at the $10 \%$ level. 


\footnotetext{
${ }^{1}$ We do not address perception about less concrete objects such as motives, which has been studied by Hao and Houser (2017) and others. Nor do we address the possibility that, although perceptions themselves are consistent with the data, their mapping into belief formation is distorted (Saponara 2018). The distinction is moot for our purposes.

${ }^{2}$ Statistical data on land uses usually come with some lag in time and at aggregate levels. For example, in the United States, the "National Resources Inventory (NRI) program collects and produces scientifically credible information on the status, condition, and trends of land, soil, water, and related resources" on the nation's non-federal lands (USDA-NRCS, 2021). The NRI data has been collected every five years from 1982 to 1997, and then annually for later years. NRI data are survey data that allow statistically reliable inferences at the county level, not at specific locations. The CropScape platform available from USDA provides detailed spatial and annual data on land uses and land use changes (USDA-NASS 2021a). But using the data requires GIS and analytical skills which an average farmer may not have or may not be willing to invest time for.

${ }^{3}$ Here we can assume that this is a different grassland parcel that farmer $i$ owns and is using it for grass at $t=1$. With this adjustment, the mathematical terms in this section will be modified, but the main analysis would be the same if a farmer owns multiple parcels with different $\theta$ values.

${ }^{4}$ By convention, user accuracy [i.e., the proportion of area identified as in a category that is actually in the category, see Olofsson et al. (2013)] is applied to assess data reliability. User accuracy was over $95 \%$ for corn and soybeans for 2014 in the Dakotas (USDA-NASS 2021b). For grass, the CDL overlays its agricultural classes on the National Land Cover Database (NLCD) grass data. User accuracy is not available for grass and is considered to be lower than those for corn and soybean. It is important to note that these accuracy numbers are at the pixel-level $(30 \mathrm{~m}$ by $30 \mathrm{~m})$. The statistics used in our analysis pertain to land cover for a 5-mile radius that is comprised of over 200,000 pixels. At this scale of spatial averaging, errors aggregate out.

${ }^{5}$ According to Arora et al (2018), NASS warns against the use of non-agricultural classes such as Grass/Pasture and Fallow/Idle as these classes have low classification accuracy. Rather, NASS suggests substituting NLCD's non-agricultural classes.

${ }^{6}$ Results are available upon request.

${ }^{7}$ The response rate was lower for questions about a respondent's local area, perhaps because farmers were less sure about information beyond their operation or because the question was asked later in the survey.
} 